\section{Isolation and identification of yeasts in white cheese}

\section{ABSTRACT}

In this study, firstly yeast was isolated from 50 white cheese samples produced by traditional methods from raw milk. The yeast species were isolated from 50 traditional white cheese samples and identified with the VITEK2 Compact system. There were obtained from white cheese samples 90 isolates 35.6\% Candida sake, $13.3 \%$ Candida zeylanoides, $8.9 \%$ Candida famata and $8.9 \%$ Candida kefyr and the remaining $33.3 \%$ Candida sphaerica, Candida colliculasa, Candida boidinii, Candida lusitaniae, Candida parapsilosis, Candida sphaerica, Cryptococcus laurentii, Candida krusei, and Saccharomyces cerevisiae. Yeasts are known as a saprophyte found in many foods, but that some of them positively contribute to the fermentation. More over some yeasts are could be used of starter culture during the manufacture of certain dairy product for maturation by supporting the functions. some yeasts species were isolated in this study, could be used as support culture.

Keywords: Candida spp., cheese, yeast

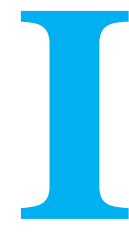

\section{NTRODUCTION}

Yeasts, which play important roles in the production and deterioration of many dairy products, are an important member of microflora ( Jakobsen \& Narvhus, 1996; Cosentino et al., 2001). Yeasts contribute to the aroma formation in dairy products with the aroma compounds and other metabolites they have ( Gadaga et al., 2001; Fröhlich-Wyder et al., 2019). Cheese is the most frequently isolated yeast product among dairy products. The reason for this may be because dairy enterprises are suitable for yeast development. In addition, it is also considered that cheese brine is an important source for yeast contamination (Kesenkaş \& Akbulut, 2006; Haastrup et al., 2018).

The role of yeasts in cheese varies depending on the type of cheese produced. Some yeast types cause deterioration in cheese like discoloration, fruity flavor, and adhesive structure formation; some other yeast types contribute to the development of tissue and flavor compounds by taking part in the maturation process ( Ferreira \& Viljoen, 2003; Atanassova et al., 2016). It is considered that yeasts can be used as auxiliary starter cultures during production stage because of their positive contributions to cheese. Kluyveromyces marxianus, Debaryomyces hansenii, Saccharomyces cerevisiae, Yarrowia lipolytica, Trichosporon cutaneum (Trichosporon beigelii), Rhodotorula mucilaginosa, Torulaspora delbrueckii are the most common yeast species (Jakobsen \& Narvhus, 1996).

\section{How to cite this article}

Gelen, US., Ceylan Z (2021). Isolation and identification of yeasts in white cheese. Journal of Advances in VetBio Science and Techniques, 6(2), 100-105. https://doi.org/10.31797/vetbio.907007
Research Article

Sevda URÇAR GELEN ${ }^{1 a}$

Ziya CEYLAN ${ }^{2 b}$

${ }^{1}$ Department of Food Hygiene and Technology, Veterinary Medicine, Atatürk University 25240 Erzurum, Turkey ${ }^{2}$ Department of Food Hygiene and Technology, Veterinary Medicine, Atatürk University 25240 Erzurum, Turkey

ORCIDa0000-0002-1852-3614 b0000-0001-8644-5905

\section{Correspondence}

Sevda URÇAR GELEN

surcar@atauni.edu.tr

Article info

Submission: 31-03-2021

Accepted: 14-06-2021

Online First: 25-08-2021

e-ISSN: 2548-1150

doi prefix: $10.31797 /$ vetbio

- http://dergipark.org.tr/vetbio

This work is licensed under a Creative Commons Attribution 4.0 International License (c) (i) 
Cosentino et al. isolated Debaryomyces hansenii, Geotrichum candidum, Kluyveromyces lactis, Kluyveromyces marxianus, Pichia, Candida, Dekkera, Yarrowia and Rhodotorula from different cheese varieties (Cosentino et al., 2001). The most frequently isolated species of fresh cheese samples were Candida zeylanoides, Debaryomyces hansenii, Kluyveromyces marxianus, Yarrowia lipolytica (Lopandic et al., 2006).

Fadda et al. conducted a study on feta cheese samples, and isolated Kluyveromyces lactis, Debaryomyces hansenii, Dekkera anomala, Dekkera bruxellensis, Geotrichum candidum, Kluyveromyces marxianus, Rhodotorula rubra, Candida tropicalis, and Candida sake (Fadda et al., 2001). In a study that was conducted in feta cheese by Kaminarides and Laskos, it was determined that Saccharomyces cerevisiae, Candida famata, Torulaspora delbrueckii, and Pichia membranaefaciens were dominant in brine juice (Kaminarides \& Laskos, 1992).

In a study conducted in Egypt, Issatchenkia orientalis, Candida albicans, Clavispora lusitaniae (Candida lusitaniae), Kodamaea ohmeri (Pichia ohmeri), Kluyveromyces marxianus and Candida catenulata were isolated from cheese (El-Sharoud, Belloch, Peris, \& Querol, 2009). In a study in Denmark, Debaryomyces hansenii, Kluyveromyces lactis, Torulaspora delbrueckii, and Yarrowia lipolytica were isolated from cheese (Westall \& Filtenborg, 1998). Cardozo et al., it was determined that Candida, Myxozyma, and Debaryomyces species were dominant in soft cheeses (Cardozo, Fusco, \& Carrasco, 2017). Karasu Yalcin et al. were identified Candida, Geotrichum and Trichosporon yeast species from traditional Mihalic cheeses (Karasu Yalcin et al., 2017 ). In a study in Portuguese, Debaryomyces hansenii, Kluyveromyces marxianus, Candida spp. and Pichia spp. were isolated from Serpa cheeses (Dos Santos, Benito, de Guía Córdoba, Alvarenga, \& de
Herrera, 2017). On the other study was found $S$. cerevisiae, Wickerhamomyces anomalus, Pichia kudriavzevii, Kluyveromyces lactis, Geotrichum candidum, Debaryomyces hansenii, Candida tropicalis, Cryptococcus neoformans, Rhodotorula glabrata and Trichosporon cutaneum (Helmy et al., 2019). Ozmen Togay et al. were isolated Torulaspora delbrueckii and Candida zeylanoides from white cheeses (Ozmen Togay et al., 2020).

Yeast types vary in the environment depending on the cheese types, production techniques, and production locations. Yeasts can have both positive and negative effects on cheese with their proteolytic and lipolytic activities. While they contribute to the maturation of some cheeses, they also cause some to deteriorate. For this reason, it is important to determine the yeast profile in cheese produced with traditional methods. In this study, the purpose was to determine the yeast flora of white cheese, which is a soft cheese consumed extensively in Turkey.

\section{MATERIAL and METHOD}

The white cheese samples used in the study were produced in local businesses with traditional methods from raw milk. Yeasts were isolated from 50 samples of White Cheese. For isolation twenty five grams of the samples was homogenized with $225 \mathrm{ml}$ of Ringer solution. Samples were serially diluted in the physiological solution and plated on a RBC (Rose Bengal Chloramphenicol) Agar (Merck). The colony forming units (cfu) were determined after incubation for 5 days at $25 \pm 1{ }^{\circ} \mathrm{C}$. From the primary cultures different colonies with identical morphological appearance were selected for further purification. The selected colonies were inoculated on a RBCA medium and after incubation at $25 \pm 1^{\circ} \mathrm{C}$ for 5 days. Strains for identification were selected based on the morphological and physiological characterisation. The suspension prepared with 
pure yeast cultures was loaded into yeast cards. Finally, all the yeast isolates were subjected to identification using the Vitek2 Compact system (bioMérieux). The test panels (ID-YST) contained 46 fluorimetric tests that included carbon source utilization, enzymatic activities and resistance (Pincus, 2006).

\section{Statistical analyses}

SPSS for Windows 21.0 was used. The physicochemical data were analysed by a oneway analysis of variance (ANOVA) was used for the microbiological data.

\section{RESULTS}

The 90 isolates that were obtained from white cheese samples were Candida sake (32\%) at a rate of $35.6 \%$, Candida zeylanoides (12) at a rate of $13.3 \%$, candida famata (8) at a rate of 8.9\%; Candida kefyr (8) at a rate of $8.9 \%$; and the rest $33.3 \%$ consisted of Candida sphaerica (4), Candida colliculasa (2), Candida boidinii (2), Candida lusitaniae (4), Candida parapsilosis (2), Candida sphaerica (4) Cryptococcus laurentii (4), Candida krusei (4) and Saccharomyces cerevisiae (4) yeasts. The yeast types, which were derived from white cheese samples, are given in Table 1.

Table 1: The yeast types, which were derived from white cheese samples

\begin{tabular}{|ccccc|}
\hline Yeast species & Number of yeast & $\begin{array}{c}\text { Percentage } \\
\text { of total }\end{array}$ & $\begin{array}{c}\text { Number of } \\
\text { samples with yeast }\end{array}$ & $\begin{array}{c}\text { Percentage of } \\
\text { Sample with yeast }\end{array}$ \\
\hline Candida sake & 32 & 35.6 & 18 & 36 \\
\hline Candida zeylanoides & 12 & 13.3 & 4 & 8 \\
\hline Candida sphaerica & 8 & 8.9 & 4 & 8 \\
\hline Candida famata & 8 & 8.9 & 4 & 8 \\
\hline Candida kefyr & 8 & 8.9 & 2 & 4 \\
\hline Candida krusei & 4 & 4.4 & 4 & 8 \\
\hline Candida lusitaniae & 4 & 4.4 & 3 & 6 \\
\hline Cryptococcus laurentii & 4 & 4.4 & 3 & 4 \\
\hline Saccharomyces cerevisiae & 4 & 4.4 & 2 & 6 \\
\hline Candida boidinii & 2 & 2.2 & 2 & 4 \\
\hline Candida colliculasa & 2 & 2.2 & 2 \\
\hline Tandida parapsilosis & 2 & 2.2 & 50 \\
\hline
\end{tabular}

\section{DISCUSSION}

The yeasts that can develop in dairy products have positive effects on ripening with their physiological and biochemical properties like lactose fermentation or assimilation, high lipolytic and proteolytic activity, lactic acid and citric acid, the ability of developing at low temperatures and tolerating high salt concentrations (Fleet, 1990; Fröhlich-Wyder et al., 2019). Yeasts vary depending on the cheese type they are isolated from. The white cheese used in this study had similarities to feta cheese.

Candida sake, which was isolated from many white cheese samples, was similarly isolated from Danish feta cheese, although not dominant in Sardinian feta cheese, this yeast species was also isolated ( Westall \& Filtenborg, 1998; Fadda et al., 2001). Although Candida zeylanoides, which was isolated in this study, is one of the most isolated yeast species in studies on both soft and hard cheese varieties, its lactose and lactate are negative ( Seiler \& 
Busse, 1990; Pereira-Dias et al., 2000; Callon et al., 2006; Lopandic et al., 2006; Karasu-Yalcin et al., 2017; Dos Santos et al., 2017; Ozmen Togay et al., 2020)

Candida famata species, which were reported to contribute to aroma formation in cheese, have previously been isolated at similar rates in studies conducted on different cheese varieties (Besancon et al., 1992; Pereira-Dias et al., 2000; Romano et al., 2001; Atanassova et al., 2016; Karasu-Yalcin et al., 2017; Dos Santos et al., 2017; Helmy et al., 2019; Ozmen Togay et al., 2020). Candida famata (perfect form is Debaryomyces hansenii) may be used as a starter culture to help in cheese production as it can assimilate lactose, lactic and citric acids, produce lipoidase and proteases and develop in high salt concentrations and low $\mathrm{pH}$ values (Fatichenti et al., 1983; Welthagen \& Viljoen, 1999; Van Den Tempel \& Jakobsen, 2000). Candida kefyr (perfect form is Kluyveromyces marxianus) was a yeast species that was often isolated, even if it is not dominant flora, in studies conducted in different cheese varieties, as it was the case in this study ( Welthagen \& Viljoen, 1997; Welthagen \& Viljoen, 1998; Romano et al., 2001; Callon et al., 2006; Atanassova et al., 2016; Dos Santos et al., 2017; Ozmen Togay et al., 2020). Candida kefyr, which can ferment lactose, is usually available in milk and dairy products. It encourages reproduction in cheese where other yeasts are low especially because they can ferment lactose (Padilla et al., 2014).

Saccharomyces cerevisiae (Callon et al., 2006; Atanassova et al., 2016; Helmy et al., 2019; Ozmen Togay et al., 2020), Candida colliculasa (Romano et al., 2001), Candida sphaerica (Besancon et al., 1992), Candida lusitaniae (Facchin et al., 2013) Candida krusei (Facchin et al., 2013; Karasu-Yalcin et al., 2017) and Candida parapsilosis (Seiler \& Busse, 1990; Callon et al., 2006; Facchin et al., 2013; Dos Santos et al., 2017; Ozmen Togay et al., 2020) were found in different cheese varieties as in previous studies but were not dominant.

\section{CONCLUSION}

As a result, we determined in our study that Candida spp. constituted the predominant yeast flora in white cheeses. Yeasts have effects on both ripening and deterioration in cheese. For this reason, firstly the yeast profile in cheese must be determined, and then it should be determined which yeast species can be used as auxiliary starters in different cheese types. In this way, both the ripening time will be shortened, and the products will be more aromatic.

\section{ACKNOWLEDGMENT}

Ethical approval: This article doesn't contain any examinations with animal members or creatures performed by any of the writers.

Conflict of interest: The authors declared that there is no conflict of interest.

\section{KAYNAKLAR}

Atanassova, M., Fernández-Otero, C., RodríguezAlonso, P., Fernández-No, I., Garabal, J., \& Centeno, J. (2016). Characterization of yeasts isolated from artisanal short-ripened cows' cheeses produced in Galicia (NW Spain). Food Microbiology, 53, 172-181.

Besancon, X., Smet, C., Chabalier, C., Rivemale, M., Reverbel, J., Ratomahenina, R., \& Galzy, P. (1992). Study of surface yeast flora of Roquefort cheese. International Journal of Food Microbiology, 17(1), 9-18. Retrieved from https://www.sciencedirect.com/science/article/abs/pii/ 016816059290014T?via\%3Dihub.

Callon, C., Delbes, C., Duthoit, F., \& Montel, M. C. (2006). Application of SSCP-PCR fingerprinting to profile the yeast community in raw milk Salers cheeses. Syst Appl Microbiol, 29(2), 172-180. doi:10.1016/j.syapm.2005.07.008.

Cardozo, M. C., Fusco, Á. J., \& Carrasco, M. S. (2017). Yeast microbiota in artisanal cheeses from Corrientes, Argentina. Revista Argentina de microbiologia, 50(2), 165-172.

Cosentino, S., Fadda, M. E., Deplano, M., Mulargia, A. F., \& Palmas, F. (2001). Yeasts associated with Sardinian ewe's dairy products. International Journal of Food Microbiology, 69(1-2), 53-58. doi:Doi 10.1016/S0168-1605(01)00572-4. 
Dos Santos, M. T. P. G., Benito, M. J., de Guía Córdoba, M., Alvarenga, N., \& de Herrera, S. R.M. S. (2017). Yeast community in traditional Portuguese Serpa cheese by culture-dependent andindependent DNA approaches. International journal of food microbiology, 262, 63-70.

El-Sharoud, W. M., Belloch, C., Peris, D., \& Querol, A. (2009). Molecular Identification of Yeasts Associated with Traditional Egyptian Dairy Products. Journal of Food Science, 74(7), M341-M346. doi:DOI 10.1111/j.1750-3841.2009.01258.x.

Facchin, S., Barbosa, A. C., Carmo, L. S., Silva, M. C. C., Oliveira, A. L., Morais, P. B., \& Rosa, C. A. (2013). Yeasts and hygienic-sanitary microbial indicators in water buffalo mozzarella produced and commercialized in Minas Gerais, Brazil. Brazilian Journal of Microbiology, 44(3), 701-707. Retrieved from

http://www.ncbi.nlm.nih.gov/pmc/articles/PMC39101 77/pdf/bjm-44-701.pdf

Fadda, M. E., Cosentino, S., Deplano, M., \& Palmas, F. (2001). Yeast populations in Sardinian feta cheese. International Journal of Food Microbiology, 69(1-2), 153-156. 1605(01)00586-4.

Fatichenti, F., Bergere, J. L., Deiana, P., \& Farris, G. A. (1983). Antagonistic activity of Debaryomyces hansenii towards Clostridium tyrobutyricum and $\mathrm{Cl}$. butyricum. Journal of dairy research, 50(4), 449-457. Retrieved

from http://journals.cambridge.org/action/displayAbstract?f $\underline{\text { romPage }=\text { online } \& \text { aid }=5148676 \& \text { fileId }=\text { S0022029900 }}$ $\underline{032684 .}$.

Ferreira, A. D., \& Viljoen, B. C. (2003). Yeasts as adjunct starters in matured Cheddar cheese. International Journal of Food Microbiology, 86(1-2), 131-140. doi:Doi 10.1016/S0168-1605(03)00252-6.

Fleet, G. H. (1990). Yeasts in Dairy-Products. Journal of Applied Bacteriology, 68(3), 199-211. doi:DOI 10.1111/j.1365-2672.1990.tb02566.x.

Fröhlich-Wyder, M. T., Arias-Roth, E., \& Jakob, E. (2019). Cheese yeasts. Yeast, 36(3), 129-141.

Gadaga, T. H., Mutukumira, A. N., \& Narvhus, J. A. (2001). Growth characteristics of Candida kefyr and two strains of Lactococcus lactis subsp lactis isolated from Zimbabwean naturally fermented milk. International Journal of Food Microbiology, 70(1-2), 11-19. doi:Doi 10.1016/S0168-1605(01)00501-3.

Haastrup, M. K., Johansen, P., Malskar, A. H., Castro-Mejía, J. L., Kot, W., Krych, L., . . . Jespersen, L. (2018). Cheese brines from Danish dairies reveal a complex microbiota comprising several halotolerant bacteria and yeasts. International journal of food microbiology, 285, 173-187.

Helmy, E., Soliman, S., Abdel-Ghany, T. M., \& Ganash, M. (2019). Evaluation of potentially probiotic attributes of certain dairy yeast isolated from buffalo sweetened Karish cheese. Heliyon, 5(5), e01649. Retrieved from https://www.ncbi.nlm.nih.gov/pmc/articles/PMC6520 606/pdf/main.pdf.
Jakobsen, M., \& Narvhus, J. (1996). Yeasts and their possible beneficial and negative effects on the quality of dairy products. International Dairy Journal, 6(8-9), 755-768. doi:Doi 10.1016/0958-6946(95)00071-2.

Kaminarides, S. E., \& Laskos, N. S. (1992). Yeasts in factory brine of feta cheese. Aust. J. Dairy Technol., 47 (1) 68-71.

Karasu-Yalcin, S., Senses-Ergul, S., \& Ozbas, Z. Y. (2017). Enzymatic characterization of yeast strains originated from traditional Mihalic cheese. $J$ Microbiol Biotech Food Sci 6 (5) 1152-1156.

Kesenkaş, H., \& Akbulut, N. (2006). Destek kültür olarak kullanılan bazı mayaların beyaz peynir aroması üzerine etkileri. Ege Üniv. Ziraat Fak. Derg, 43(2), 73-84.

Lopandic, K., Zelger, S., Bánszky, L. K., EliskasesLechner, F., \& Prillinger, H. (2006). Identification of yeasts associated with milk products using traditional and molecular techniques. Food Microbiology, 23(4), 341-350. doi:http://dx.doi.org/ $\underline{\text { 10.1016/j.fm.2005.05.001. }}$

Ozmen Togay, S., Capece, A., Siesto, G., Aksu, H., Sandikci Altunatmaz, S., Yilmaz Aksu, F., Romano P., Karagul Yuceer, Y. (2020). Molecular characterization of yeasts isolated from traditional Turkish cheeses. Food Science and Technology(AHEAD).

Padilla, B., Belloch, C., Lopez-Diez, J. J., Flores, M., \& Manzanares, P. (2014). Potential impact of dairy yeasts on the typical flavour of traditional ewes' and goats' cheeses. International Dairy Journal, 35(2), 122-129. doi:DOI 10.1016/j.idairyj.2013.11.002.

Pereira-Dias, S., Potes, M. E., Marinho, A., MalfeitoFerreira, M., \& Loureiro, V. (2000). Characterisation of yeast flora isolated from an artisanal Portuguese ewes' cheese. International Journal of Food Microbiology, 60(1), 55-63. doi:Doi 10.1016/S0168-1605(00)00323-8.

Pincus, D. H. (2006). Microbial identification using the bioMerieux VITEK ${ }^{\circledR} 2$ System. Encyclopedia of Rapid Microbiological Methods. Bethesda, MD: Parenteral Drug Association.

Romano, P., Ricciardi, A., Salzano, G., \& Suzzi, G. (2001). Yeasts from Water Buffalo Mozzarella, a traditional cheese of the Mediterranean area. International Journal of Food Microbiology, 69(1-2), 45-51.

Seiler, H., \& Busse, M. (1990). The yeasts of cheese brines. International Journal of Food Microbiology, 11(3-4), 289-303. Retrieved from https://www.sciencedirect.com/science/article/abs/pii/ 016816059090022W?via\%3Dihub.

Van Den Tempel, T., \& Jakobsen, M. (2000). The technological characteristics of Debaryomyces hansenii and Yarrowia lipolytica and their potential as starter cultures for production of Danablu. International Dairy Journal, 10(4), 263-270. doi:http://dx.doi.org/10.1016/S0958-6946(00)00053$\underline{4}$.

Welthagen, J. J., \& Viljoen, B. C. (1997). The value of certain chemotaxonomic methods in the identification of food related yeasts. Food Microbiology, 14(3), 231-245. doi:DOI 10.1006/fmic.1996.0087. 
Welthagen, J. J., \& Viljoen, B. C. (1998). Yeast profile in Gouda cheese during processing and ripening. International Journal of Food Microbiology, 41(3), 185-194. doi:http://dx.doi.org/10.1016/S01681605(98)00042-7.

Welthagen, J. J., \& Viljoen, B. C. (1999). The isolation and identification of yeasts obtained during the manufacture and ripening of Cheddar cheese. Food Microbiology, 16(1), 63-73. doi:DOI 10.1006/fmic.1998.0219.

Westall, S., \& Filtenborg, O. (1998). Yeast occurrence in Danish feta cheese. Food Microbiology, 15(2), 215-222. doi:http://dx.doi.org/10.1006/fmic.1997. $\underline{0161 .}$. 